\title{
Restauro e integridade: do concreto ao efêmero
}

Restoration and integrity: from concrete to ephemeral

hitp://dx.doi.org/10.1590/1982-02672020v28e2

JOELMIR MARQUES DA SILVA'

hitps://orcid.org/0000-0002-8323-7171

Universidade Federal de Pernambuco / Recife, PE, Brasil

RESUMO: Um dos caminhos para o entendimento da noção de integridade é a teoria do restauro por visar à unidade potencial de um bem. A integridade é uma condição para a conservação do patrimônio e vem sendo alvo de debates nas últimas décadas, mas, quando o objeto de análise são os jardins históricos, somos remetidos a outra realidade - a ausência de um aprofundamento teórico e, consequentemente, de uma metodologia para sua verificação. Tal problemática impulsionou a escrita desde artigo que traz um panorama de como a integridade está sendo pensada e discutida e como os jardins históricos estão sendo considerados ante sua efemeridade, iá que o elemento principal é o vegetal.

PALAVRAS-CHAVE: Conservação. Patrimônio. Jardim histórico.

ABSTRACT: One of the ways to understand the notion of integrity is the theory of restoration because it aims at the potential unity of cultural heritage. Integrity is a condition for the conservation of cultural heritage and has been the subject of debate in the last decades, but when the object of analysis is the historical gardens, we are referred to another reality - the absence of a

\begin{abstract}
1. Professor do Departamento de Arquitetura e Urbanismo e pesquisador do Laboratório da Paisagem, ambos da Universidade Federal de Pernambuco (UFPE). Membro do International Scientific Committee on Cultural Landscapes ICOMOS-IFLA. Biólogo. Mestre e Doutor em Desenvolvimento Urbano pela UFPE. Mestre en Diseño, Planificación y Conservación de paisajes y Jardines pela Universidad Autónoma Metropolitana - México. E-mail: <joelmir_marques@ hotmail.com>.
\end{abstract}


theoretical deepening and, consequently, of a methodology for its verification. This problematic has driven writing since an article that provides an overview of how integrity is being thought and discussed and how historical gardens are being considered in view of their ephemerality since the main element is the vegetation.

KEYWORDS: Conservation. Heritage. Historic garden. 
El jardín [...] nunca es estático, su incesante metamorfosis nos acompaña en los infinitos ciclos de la vida. La misma esencia del material vegetal radica en su versatilidad y cambio. Los jardines son irrepetibles en exactas situaciones por depender de los ciclos naturales. Crecen, maduran y mueren a la par del hombre.

Sonia Beriman²

A integridade, como uma condição para a conservação de um bem, vem sendo alvo de debates nas últimas décadas, porém, quando a direcionamos para os jardins históricos, somos remetidos a uma outra realidade - de uma lacuna na literatura pela falta de especialistas. Essa condição configura-se como um problema para a conservação.

Tal problemática se deve ao fato de que, quando tratamos de ações de conservação de jardins históricos, a autenticidade, por estar presente na Carta de Florença (1981), é o foco central dos conservadores, a fim de que possam validar as ações. Todavia, é pouca a literatura sobre a autenticidade.

De forma genérica, a autenticidade se origina na linguagem da arte no sentido de genuíno, em oposição ao que é falso ou copiado, já a integridade está mais relacionada ao significado de continuidade e honestidade em oposição a fragmentado e destruído. ${ }^{3}$

Dessa forma, direcionando a questão para o elemento principal do jardim - a vegetação -, se pergunta: a introdução de novos indivíduos no jardim, mesmo sendo pertencentes as espécies especificadas no projeto original, faz com que ele seja autêntico e, consequentemente, íntegro, ainda que a matéria não seja mais a mesma? Qual postura assumir frente às espécies vegetais que foram incluídas no jardim por uma questão de aproximação plástica às do projeto original, perde-se a autenticidade e a integridade? $\bigcirc$ que sabemos é que a substituição da vegetação é uma ação certa em algum momento da vida do jardim, principalmente as herbáceas e arbustivas por possuírem um ciclo de vida curto. A vegetação, até hoje, é uma grande interrogação na conservação do jardim histórico quando a questão é a integridade e a autenticidade.

Diante dessa problemática, busca-se entender a condição de integridade e da autenticidade e avaliar se uma condição depende ou não da outra para existir. Para tanto, a teoria da conservação - principalmente do restauro -, tanto da arquitetura como da pintura, foi considerada e adaptada para o jardim, ou seja, do concreto ao efêmero. 
4. Cf. Feilden (2004)

5. Cf. Baldini (2002).

6. Ibid. (p.7).

7. Cf. Baldini (2002)

\section{RESTAURO: A BUSCA PELA UNITÀ POTENZIALE}

De acordo com o arquiteto conservacionista Bernard Feilden, ex-diretor-geral do International Centre for the Study of the Preservation and Restoration of Cultural Property (lccrom), a conservação é a ação realizada para prevenir a deterioração e configura-se como a gestão dinâmica, compreendendo todos os atos que prolonguem a vida do patrimônio cultural e natural, ${ }^{4}$ para tal, o Canadian Code of Ethics especifica as seguintes etapas: averiguação, documentação, conservação preventiva, preservação, tratamento, restauro e reconstrução. A retenção ou reintrodução de um uso, retenção de associações e significados, manutenção, adaptação e interpretação são ações que também fazem parte do ato de conservar e que estão presentes na Carta de Burra de 1999.

Para Umberto Baldini, historiador da arte e especialista em história, teoria e técnica de restauro da Universidade Internacional de Arte de Florença, a obra de arte, durante sua vida, pode se encontrar em três estados: (i) o da destruição (thanatos) - por parte dos gestores (descuido e abandono) ou por acontecimento externo (terremoto, incêndio, caída, etc.); (ii) o da prolongação da vida (bios) - que resulta do ato físico do cuidado material da obra para protegê-la de danos e perdas (manutenção e conservação); e (iii) o da restituição de sua realidade como obra de arte (heros) que se manifesta no ato final da filologia crítica (restauro). ${ }^{5}$ Para o autor, "em qualquer obra de arte pode-se registrar pelo menos três atos: o primeiro é o da criação por parte do artista; o segundo é a ação do tempo sobre a obra; e o terceiro é a ação do homem"6 (figura 1).

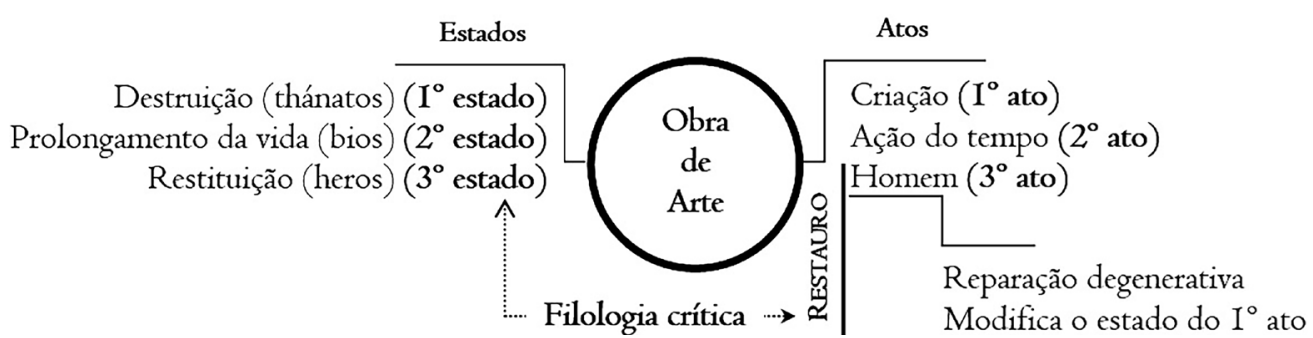

Figura 1 - Estados e Atos da obra de arte e seu direcionamento para o restauro.?

Bernard Feilden, ao tratar da intervenção ética [filologia crítica] na conservação, declara que para o patrimônio é importante considerar os seguintes aspectos: (i) o estado do bem, que deve ser documentado antes do início de uma intervenção; (ii) os materiais e métodos de intervenção, utilizados para a conservação, 
que devem ser documentados, sempre que possível; (iii) os vestígios históricos não devem ser removidos, destruídos nem falsificados; (iv) sem importar qual seja, a intervenção na estrutura deverá ser mínima, reversível ou, pelo menos, não prejudicar possíveis intervenções futuras; e (v) qualquer intervenção deve ser orientada com o máximo de respeito à integridade estética, histórica e física do bem. ${ }^{8}$

Dessa forma, Gustavo Giovannoni, em Verbete: Restauro dei Monumenti, de 1936, chama a atenção para a complexidade do ato de restaurar e para ele:

[...] o propósito de restaurar os monumentos, seja para consolidá-los - reparando-os das injúrias do tempo - seja para reconduzi-los a uma nova função de vida, é conceito de todo moderno, paralelo àquelas posturas de pensamento e de cultura que vê nos testemunhos construtivos e artísticos do passado um tema que merece respeito e que demanda cuidados. ${ }^{9}$

A ideia moderna de restauro - o chamado restauro crítico - construída no início do século XX deve-se ao arquiteto restaurador Camillo Boito e ao arquiteto Gustavo Giovannoni que contribuíram para a história do restauro, tendo ambos assumido uma posição intermediária entre os postulados do arquiteto Eugène Emmanuel Viollet-le-Duc e o do crítico de arte John Ruskin.

A primeira formulação teórica sobre restauro, chamada de restauro estilístico, se originou e teve aplicação na França entre 1830 e 1870, principalmente através do trabalho de Viollet-le-Duc, que considerava legítima todas as intervenções que visavam a repristinação ou o ideal de unidade formal do estilo do monumento. Já na Inglaterra, em meados do século XVIII, tomou forma uma visão completamente oposta, a do chamado restauro romântico tendo como maior expoente John Ruskin. Esta visão se baseia na poesia da ruína e, por conseguinte, respeito da forma atual do monumento, excluindo a legitimidade, seja da repristinação estilística, seja de qualquer intervenção que não fosse rigorosamente conservativa. ${ }^{10}$

Na Itália do século XIX duas novas posições sobre restauro se afirmaram. A primeira refutava a prática da repristinação no restauro estilístico baseada na teoria do arquiteto e historiador de arquitetura Luca Beltrami que considerava a possibilidade da reconstrução da forma particular do bem mediante análise de sua evolução. A segunda, formulada pelo arquiteto, escultor e historiador Camillo Boito, leva em consideração a teoria embasada no restauro contemporâneo, feito próprio, e votado no Congresso de Engenheiros e Arquitetos, que teve local em Roma em 1883, onde anunciou o princípio ao respeito dos agregados não originais e a ilegalidade das renovações de estilo e, caso haja necessidade desse tipo de ação, estas deveriam ser reconhecíveis. 
11. Kühl (2008, p. 64).

12. Cf. Kühl (2008; 2010).

13. Cf. Carbonara (1997).
O restauro histórico e o contemporâneo, chamados de científicos, foram recebidos na Conferência Internacional de Atenas em 1931 [Sociedades das Nações] e suas noções reelaboradas por Gustavo Giovannoni na redação da Carta de Atenas (1931) e da Carta Italiana de Restauro (1931-1932) e permaneceram como base para sucessiva elaboração metodológica, embora, na prática, por vezes, continuassem a ser implementadas medidas de repristinação. Assim, restaurar deixa de ter a conotação da busca pelo estado prístino do monumento e passa, de acordo com Beatriz Mugayar Kühl," a "respeitar plenamente qualquer obra reconhecida como bem a tutelar, em suas várias estratificações e em seu transcurso ao longo do tempo, independente da maior ou menor apreciação pelo seu valor 'artístico', algo reiterado na Carta de Veneza, de 1964".

Com o passar do tempo, ficou claro que para o tema restauro não existiu uma linearidade nem uma homogeneidade em seus fundamentos, contudo ocorreram intercâmbios entre a teoria e a prática e alguns modi operandi, que passaram a ser considerados, após estudos, nas intenções de restauro. Um momento muito importante desse processo ocorreu na primeira metade do século XX, que foi um período em que se realizou uma ampla reelaboração dos conceitos em vigor. ${ }^{12}$

Seguindo o pensamento de Giovanni Carbonara em II restauro scientifico nella prima metà del XX secolo, ${ }^{13}$ tais processos foram consequências dos inúmeros problemas acarretados pela última Guerra Mundial que evidenciou a não aplicabilidade geral, a partir de novas cognições, do pensamento sobre a arte e, depois, sobre a arquitetura, o que demonstrou a irrelevância e os limites do restauro científico. $\bigcirc$ que não quer dizer que seus princípios científicos se tornaram inválidos ou são aparentemente falsos, eles só têm sido, com razão, julgados como reducionistas e incapazes de entendimento, guiando, consequentemente, o modo de intervenção e a complexa realidade artística e documental do monumento. Assim, essa visão de restauro passa a ter uma conotação mais filológica que científica, no sentido pleno do termo, atrelada a uma forma de entender a arte e, especialmente, a arquitetura, substancialmente positivista e classificatória, atento ao aspecto evolutivo e estilístico, mas insuficiente para fins da compreensão profunda da história do monumento.

É a partir de meados do século XX que a discussão ganha amplitude, consistência e profundidade, quando ocorreu a busca pela superação das visões do restauro que, na linha teórica predominante, estavam direcionadas aos aspectos documentais, porém, em muitos casos operavam na prática; a ação era tida como algo de caráter empírico que procurava reverter o curso do tempo e que mostrava a aversão ao envelhecimento. Desse modo, passa-se a encarar o restauro como um ato histórico-crítico, em que os aspectos materiais, formais e documentais do 
bem eram considerados, respeitando as várias fases pela qual passou, preservando sua pátina. É importante observar que, nesse momento, qualquer ação no bem intervém de maneira inflexível em sua realidade figurativa, e o restauro assume, para si, a tarefa de prefigurar, controlar e justificar as alterações. Assim, autores como Cesare Brandi, Roberto Pane, Renato Bonelli e Paul Philippot foram fundamentais nessa nova abordagem, atingindo certa posição e consenso internacional na Carta de Veneza. ${ }^{14}$

Nesse ínterim, Brandi - que construiu seus enunciados tomando por base a estética, a historiografia e a crítica da arte - foi o motor para que outros estudiosos da corrente do restauro crítico solidificassem suas ideias ante as transformações pelas quais o tema restauro estava passando, agregando em seus pensamentos a corrente da estética. De tal modo, a ênfase foi dada aos valores formais com predominância ao valor documental da obra, respeitando, dessa forma, os aspectos históricos e as várias fases pelo qual passou o monumento. Aborda-se o restauro de forma articulada e não subdividida em categorias como propôs Gustavo Giovannoni: "restauros de consolidação", "restauros de recomposição (anastilose)", "restauros de liberação" e "restauros de renovação", 15 o que pode ser constatado na diferença de redação da Carta de Atenas (1931) e da Carta de Veneza (1964) "em que, por exemplo, não mais aparece a distinção entre "monumentos vivos" e "monumentos mortos". 16

Segundo Silva, ${ }^{17}$ a questão monumentos vivos foi discutida de forma pioneira durante o II International Congress of Restoration em 1964, ocasião em que foi elaborada a Carta de Veneza. Nesse momento, o arquiteto Mario Berucci em Il monumento vivo de 1964 e o historiador da arte Luigi Maria Crespi em Monumenti vivi o morti de 1964 tecem uma análise crítica sobre a condição de vivo ou morto dos monumentos, muito em moda até então, e que tinha como respaldo, principalmente, as opiniões apresentadas pelo arquiteto Lovis Martial Adrien Ghislain Cloquet em La restauration des monuments anciens de 1901. Para Cloquet, os monumentos vivos seriam aqueles que ainda estariam em uso, fazendo parte da vida da cidade, e mortos os que não possuíam nenhuma função cotidiana, a exemplo das ruínas e remanescentes da Antiguidade Clássica. ${ }^{18}$

De acordo com Luigi Crespi, todos os monumentos devem ser considerados como vivos, uma vez que representam um tempo histórico, possuem valores e proclamam uma espiritualidade. $\bigcirc$ referido autor cita como exemplo Pompeia, o Parthenon e o Fórum Romano para firmar sua teoria. ${ }^{19}$ Já para Mario Berucci um monumento vivo é "uma lembrança que ao longo do século, apesar de ter sido adulterado e alterado, mantém-se o seu propósito original de modo que ainda hoje é usado, como se permanecesse completamente inalterado". Indo mais além, Berucci
14. Cf. Kühl (2008).

15. Giovannoni (1936, p. 196-197).

16. Ibid. (p. 67).

17. Cf. Silva (2017b).

18. Ibid..

19. Crespi (1964, p. 7 apud Silva, 2018, p. 26). 
20. Berucci (1964, p. 1-4 apud Silva 2018, p. 26).

21. Cf. Luciani (1988).

22. Cf. Brandi (2004).

23. Ibid., p. 30.

24. Cury (2000, p. 94).

25. Carta do Restauro (1972, Art. $1^{\circ}$ ).

26. Brandi (2004, p. 228).

27. Ibid., p. 29. entra na questão da conservação e considera que o objetivo primordial é manter o monumento vivo "em pleno funcionamento, para que possa nos dar uma atmosfera ao mesmo tempo física e espiritual" e recomenda ações como: (i) "manutenção e adaptação [...]; (ii) restauro estético [...]; e (iii) reconstrução parcial" .20

Gustavo Giovannoni, assim como Camillo Boito, tinha como fundamento o estudo documental e a observação calcados no historicismo pela análise formal e técnico-construtiva em relação aos elementos compositivos da construção primitiva. ${ }^{21}$ É, porém, com Brandi, na década de 1960, que é introduzida a relação entre o restauro e a obra de arte, quando se impõe a discussão da preponderância da instância estética, que tem por base a condição de obra de arte, sobre a instância histórica, que atrela a produção humana ao tempo e ao lugar. ${ }^{22} \mathrm{E}$, quando se trata de arte, a estética prevalece sobre a história.

O restauro "constitui o momento metodológico do reconhecimento da obra de arte, na sua consistência física e na sua dúplice polaridade estética e histórica, com vistas à sua transmissão para o futuro". ${ }^{23}$ É um processo coletivo que exige profundo conhecimento da técnica, da história, da estética e da filosofia, ao qual não se pode assegurar a legitimidade das escolhas realizadas nos procedimentos. Dessa forma, o que deve guiar o restauro é um juízo crítico de valor, ideia presente já no pensamento de Aloïs Riegl em $O$ culto moderno dos monumentos: sua essência e sua gênese de 1903 e que aparece no Art. 11 da Carta de Veneza (1964) complementada pela advertência de que "o julgamento do valor dos elementos em causa e a decisão quanto ao que pode ser eliminado não podem depender somente do autor do projeto". ${ }^{24}$

Um grande avanço na teoria brandiana se deu ao fato da ampliação, apresentada na Carta do Restauro (1972), ${ }^{25}$ do conceito de obra de arte "que vai dos monumentos arquitetônicos aos de pintura e escultura, mesmo se em fragmentos, e do remanescente paleolítico às expressões figurativas das culturas populares e da arte contemporânea". ${ }^{26}$ Desta forma, possibilita a aplicação da teoria geral do restauro e da conservação da obra de arte para o jardim histórico. Somando esses pontos ao entendimento de que o próprio restauro terá, pois, o seu conceito articulado "não com base nos procedimentos práticos que caracterizam o restauro de fato, mas com base no conceito da obra de arte de que recebe a qualificação [...] pelo fato de a obra de arte condicionar o restauro e não o contrário", 27 faz com que seja possível tomar por base seus princípios e rebatê-los na conservação de jardins históricos.

Com o First International Symposium on Protection and Restoration of Historic Gardens, em 1971, e a elaboração da Carta do Restauro, amplia-se a noção de patrimônio para jardins e parques. Contudo, a preocupação com o restauro de jardins 
históricos só é devidamente abordada na Carta de Florença (1981) elaborada pelo International Council of Monuments and Sites e pelo International Scientific Committee on Historic Gardens and Sites $(\mid \mathrm{comos} / \mathrm{|fla})^{28}$ com o objetivo de protegê-los.

Em 1984, o International Council of Museums (lcom) especifica que a atividade do conservador-restaurador compreende o Exame técnico, a Preservação e o Restauro, ações devidamente circunscritas e apresentadas por ordem de prioridade.

O Exame é o procedimento preliminar efetuado para determinar o significado documental de um artefato, estrutura e materiais, amplitude da sua deterioração, alteração e perda e a documentação desses resultados. A Preservação envolve as medidas tomadas para retardar ou prevenir a deterioração ou danos de bens culturais através do controle do meio ambiente e/ou tratamento da sua estrutura, com a finalidade de os manter, tanto quanto possível, num estado inalterado. $\bigcirc$ Restauro, etapa final, facilita o entendimento do bem, sendo considerado como a ação empreendida para tornar compreensível um artefato deteriorado ou danificado, com o mínimo de sacrifício da sua integridade estética e histórica. ${ }^{29}$

No curso da história, a temática inerente ao restauro de jardim histórico foi desenvolvida através de um confronto dialético estreito entre atitudes pragmáticas e diferentes posiç̃ões teóricas. ${ }^{30} \mathrm{~A}$ primeira formulação importante sobre $\mathrm{O}$ tema da conservação dos jardins remonta ao tratado de Antoine Joseph Dezallier d'Argenville, denominado La théorie et la pratique du jardinagem, de 1709, ${ }^{31}$ que constitui uma precoce, mas interessante, reflexão sobre o tema do restauro. Conforme o sociólogo Michel Conan, ${ }^{32}$ o tratado de Antoine Joseph Dezallier d'Argenville já pontuava a importância preliminar da observação do status quo do jardim, além da necessidade de novas intervenções conforme o princípio moderno de neutralidade. Segundo Giusti, ${ }^{33}$ é somente nos séculos XVIII e XIX, e com a ideia de jardim-monumento, que se confere uma abordagem com maior rigor cientifico e objetivo para o restauro de jardim histórico.

No que se refere ao processo de restauro de jardim histórico "é preciso aliar-se à marca de quem o concebeu, de quem o construiu, e de quem o manteve, e respeitá-la como um fator tão fundamental como os processos naturais, e certamente mais importantes que a própria intervenção de restauro" ${ }^{34}$ Isso significa possibilitar o reconhecimento da ideia do paisagista a partir do resgate dos seus princípios projetuais e segundo os limites do material existente, principalmente no que alude à vegetação. Assim, a ideia do paisagista estará mantida, e, por isso, os ajustes se justificam.

Recorrendo a Brandi, mais precisamente sobre as instâncias do restauro - a estética e a histórica -, em um sentido à materialidade, uma vez que é por meio dessa materialidade que a imagem [composição] da obra de arte pode ser
28. Em 1999 o Comitê Executivo do Icomos aprova a mudança do nome para International Scientific Committee on Cultural Landscapes (ISCCL).

29. Cf. Icom-CC (1984).

30. Cf. Giusti (2004).

31. Obra original disponível na base de dados da Biliothèque Nationale de France.

32. Cf. Conan (2001).

33. Cf. Giusti (2004).

34. Monteiro; Castel-Branco; Fonseca (1999, p. 143). 
35. Park Service (1990). O National Park Service coopera com parceiros para estender os benefícios da conservação dos recursos naturais e culturais e recreação ao ar livre por todo o país e pelo mundo. Preserva os recursos naturais e culturais e valores do Sistema $\mathrm{Na}$ cional de Parques para o gozo, educação e inspiração desta e de futuras gerações.

36. Cf. Jokilehto (2006a;b e 2007).

37. Delphim in Oliveira (2007, p. 134-135).

38. Brandi (2004, p. 33).

39. Cf. Brandi (2004).

40. Cf. Carbonara (1997).

41. Bonelli (1963) apud Carbonara (1997, p. 499). transmitida para a posteridade, o primeiro axioma brandiano especifica que é somente na matéria que pode ser resolvido o conflito entre a instância estética e instância histórica. Assim, podemos remeter tal preceito à paleta vegetal dos jardins históricos, uma vez que ela se configura como o meio para a imagem, possibilitando a permanência da integridade do design apresentada no National Park Service ${ }^{35}$ ou na integridade visual de Jukka Jokilehto. ${ }^{36}$

Contudo, segundo o arquiteto Carlos Fernando de Moura Delphim, em um jardim histórico, onde sucessivas alterações vão se processando ao longo de sua vida, é necessário "primeiro verificar quão íntegro ele se encontra e, em seguida, quão autêntico. Essas são condições importantes para justificar a tomada de medidas para preservação de todo bem cultural inclusive os jardins históricos e constituem a premissa de qualquer trabalho, inclusive de tombamento". ${ }^{37}$

As palavras de Carlos Fernando de Moura Delphim refletem o segundo axioma de Brandi no qual "o restauro deve visar ao restabelecimento da unidade potencial da obra de arte, desde que isso seja possível sem cometer um falso artístico ou um falso histórico, e sem cancelar nenhum traço da passagem da obra de arte no tempo". ${ }^{38}$

Assim, a ação de restaurar uma obra de arte não significa que se tenha que trazê-la a seu estado prístino, como é sugerido por Viollet-le-Duc. Desta forma, Brandi ${ }^{39}$ sugere que o ato de restaurar seja dirigido ao restabelecimento da potencialidade artística da obra de arte como um todo. Até mesmo porque, conforme Giovanni Carbonara, ${ }^{40}$ a obra nasce na consciência do artista e depois se concretiza por determinados materiais; a ideia do artista é uma realidade pura, incorruptível, mas a matéria se degrada.

Na tentativa de uma aplicação da teoria do restauro para o jardim, o arquiteto e teórico de restauro Giovanni Carbonara em Osservazioni sul restauro dei giardini toma como ponto de partida a definição de jardim histórico do arquiteto Renato Bonelli:

Jardim histórico como obra de arte é aquele e somente aquele que o jardinista idealizou, composto e realizado, tomado no momento em que o autor considera que é feita em sua forma definitiva (coisa que pode exigir também um considerável tempo, para permitir o crescimento da essência arbórea). É apenas um, e sua matéria não pode ser renovada. ${ }^{41}$

Carbonara, ao considerar o jardim histórico como obra de arte viva, e, analisando-o ante os postulados de Brandi, chega ao entendimento de que, tanto do ponto de vista biológico quanto do artístico o resultado do restauro não seria outro 
que uma cópia ou (re) invocação do original perdido. Assim, conclui a favor de uma concepção crítica do restauro de jardins históricos, embora sem a instância absoluta da historicidade: "quer para um estado de ruína, que muitos jardins hoje se encontram, quer para sua condição de cópias ou de expressão de literatura 'paisagística' ou 'arquitetônica do verde', não mais próximo dos trabalhos artísticos originais". ${ }^{42}$

É na historicidade que Carmen Añón-Feliú também amarra seus conceitos, uma vez que também considera que um jardim histórico assume um caráter de museu vivo, de documento histórico, que reflete uma sociedade e uma cultura que os criaram e cuja função social é justamente testemunhar a passagem da história, ${ }^{43}$ o que permite, assim, ampliar as discussões para a teoria dos monumentos.

Ao entrar na questão específica da vegetação, Carbonara ${ }^{44}$ mostra que as substituições e reposições de espécies que já não mais existem no jardim histórico, levando em conta a questão das cópias, são provavelmente mais eficazes em jardins irregulares. $\bigcirc$ interessante é que, ao considerar os jardins onde a vegetação não tem uma rigidez geométrica, o fato da inclusão de novas espécies é menos importante, uma vez que não necessitam de assumir formas idênticas às que foram substituídas. Nesse caso, percebe-se claramente que a integridade na vegetação, e referindo-se à integridade visual, nessa tipologia de jardim, é mais fácil de ser conservada.

A substituição da vegetação deve ocorrer quando existir a lacuna, terminologia empregada por Carbonara ${ }^{45}$ e Giusti ${ }^{46}$ para especificar a interrupção de uma continuidade física e simbólica [e aqui acrescento visual] do jardim. Giusti trata a lacuna tomando por base os postulados do restauro crítico, ou seja, mesmo tendo ciência de que a vegetação tem seu ciclo biológico, ainda considera necessário avaliar se é pertinente ou não o novo plantio. Já Carbonara julga que, para tratar as lacunas, a reintegração tem que ser avaliada como possível. $\bigcirc$ interessante em Carbonara é que, se a lacuna for pequena, pode-se realizar a introdução de espécies idênticas àquelas existentes, sem que haja perdas em relação à historicidade e sem que se configure um falso histórico.

Além desses aspectos, Carbonara ${ }^{47}$ e Mario Catalano e Franco Pazini ${ }^{48}$ destacam que, para os casos em que a intervenção se faça necessária, será possível usar indivíduos da mesma espécie, mas de variedade diferente, ou indivíduos de espécies diferentes que guardem certa relação plástica e dimensionais com as existentes. E, mais uma vez, vemos que a integridade para o jardim histórico é uma condição prioritária, superando a autenticidade.
42. Carbonara (1997, p. 500).

43. Cf. Añón Felíú (1993).

44. Carbonara (1997, p. 500).

45. Cf. Carbonara (1997).

46. Cf. Giusti (2004)

47. Cf. Carbonara (1997)

48. Cf. Catalano; Pazini (1999). 
49. Carrera; Uviña; Figari (2009).

50. Cury (2000, p. 94). 51. Cf. Stovel (2007)

52. Id., 1995, p. 395.

\section{A INTEGRIDADE NA CONSERVAÇÃO DO PATRIMÔNIO}

Quando se fala em conservação do patrimônio são recorrentes na literatura especializada as noções de atributos, valores, integridade, autenticidade e significância. Contudo, a integridade é a que menos vem sendo discutida em nível internacional.

Devido aos excessos cometidos na prática do restauro arquitetônico, que seguiam as tendências de Viollet-le-Duc e de Ruskin, e visando conciliar de maneira universal essas posições, tidas como extremas, é que no início da década de 1930 um grupo de cientistas se reuniu em Atenas, mediante um acordo denominado de Carta de Atenas (1931), e estabeleceu os princípios de autenticidade baseados na ideia de conservar os edifícios e os monumentos sem reconstruir nem enganar as gerações futuras. ${ }^{49}$ Por sua vez, a integridade só aparecerá, e sem nenhuma definição e diretrizes para sua verificação, no art. 14 da Carta de Veneza de 1964, onde consta que "os sítios monumentais devem ser objeto de cuidados especiais que visem a salvaguardar sua integridade e assegurar seu saneamento, sua manutenção e valorização [...]". ${ }^{50}$

Em John Ruskin, a autenticidade estava atrelada à matéria original do monumento ante sua evolução e, como ele negava o restauro, a integridade se convertia em algo não tão primordial. Já para Eugène Emmanuel Viollet-le-Duc, e por seu restauro estilístico - para garantir o mais alto grau de autenticidade conferia ao monumento a condição de completude podendo, assim, revelar sua verdade e, consequentemente, a integridade.

Muito se tem falado, nos principais encontros sobre conservação do patrimônio, de integridade/autenticidade como se esses dois verbetes fossem uma só terminologia, ${ }^{51}$ e, nos escritos que apresentam uma diferenciação vemos, muitas vezes, que são confusos.

Os critérios iniciais de avaliação do patrimônio, desenvolvidos no início dos encontros preparatórios em Morges em 1976 e em Paris em 1977, 52 solicitados por Ernest Allan Connally, então secretário-geral do lcomos, incluiu o teste de autenticidade de sítios do patrimônio cultural e as condições de integridade para o patrimônio natural como parte das exigências que devem ser atendidas para a inscrição de um bem na lista do patrimônio mundial da humanidade.

O conceito de autenticidade apresentado dentro do primeiro conjunto de critérios de avaliação do patrimônio mundial em 1978 é derivado da condição de qualificação americana de integridade, aplicada, de forma oficial, desde 1953 para o processo de avaliação de candidaturas para o Registro Nacional Americano 
de Locais Históricos pelo National Park Service que entendia a integridade como a "qualidade da composição original da obra, local de origem, e elementos intangíveis de sentimento e associação". Essa noção foi apresentada por Ronald Freeman Lee, então historiador-chefe do National Park Service, em sua conferência intitulada "The preservation of historic and architectural Monuments in the United States" durante a Reunião de Expertos sobre Sítios e Monumentos Artísticos e Históricos, em outubro de 1949.53

Em 1990, o National Park Service publica The National Register Bulletin - technical information on the National Register of Historic Places: survey, evaluation, and preservation of cultural resources -, onde a integridade aparece como "a capacidade de um bem em transmitir o seu significado" e a sua avaliação "às vezes é um julgamento subjetivo, mas deve ser sempre fundamentado em uma compreensão de características físicas de uma propriedade e como elas se relacionam com o seu significado". ${ }^{54}$

Segundo Stovel, ${ }^{55}$ acreditava-se que o uso desse conceito de integridade garantiria a inscrição somente de sítios que oferecessem testemunho de material genuíno de importantes períodos históricos e de manifestações, e limitaria a inclusão, na lista do patrimônio mundial, de lugares históricos falsos ou totalmente reconstituídos.

Enquanto a autenticidade esteve desde o início nas diretrizes operacionais da Unesco, a compreensão do que estava implícito, em termos de requisitos de avaliação, ficou muito aquém. O documento de trabalho preparado em 1978, para a primeira sessão do Comitê do Patrimônio Mundial, provocou reações nos Estados-partes. Conforme Von Droste e Bertilsson:56 "A interpretação da autenticidade foi rebatida por vários membros que consideraram que isso não implicava necessariamente manter a função original da propriedade que, para garantir a sua preservação, muitas vezes teve que ser adaptada para outras funções".

Daí em diante, Cartas, Declarações, Documentos, Princípios e Recomendações para a salvaguarda do patrimônio, resultados das discussões dos principais encontros de especialistas na área foram sendo publicados. Porém, por não terem a conotação de lei, todos esses aparatos são configurados como diretrizes, que podem ou não ser aplicadas.

Assim, de 1964 a 2015, 33 publicações, em sua grande maioria por parte do lcomos e da Unesco, abordaram a integridade, porém sem nenhuma definição clara para o verbete e/ou diretrizes para sua verificação e, consequentemente, sua conservação. ${ }^{57}$
53. Lee (1949, p. 6)

54. National Park Service (1990, p. 44).

55. Cf. Stovel (2007).

56. Von Droste; Bertilsson (1995, p. 3).

57. Para mais informações cf. Silva (2017a). 
58. Cf. Icomos-Canadá (1983).

59. Cf. Icomos (1999a).

60. Cf. Segundo Protocolo da... (1999).

61. Cf. Icomos (1999b).

62. Cf. Carta Australiana (2002).

63. Cf. Icomos/IUCN (2005).

64. Cf. Icomos (2008b).

65. Cf. Icomos-Nova Zelândia (2010a).

66. Cf. Jokilehto (1993; 1994; 1995; 2002; 2004; 2005; 2006; 2007).

67. Cf. Stovel (1995; 2005; 2007).

68. National Park Service (1990, p. 2).

69. Cf. Icomos (1996).

70. Cf. Icomos (2008a).

71. Cf. Icomos-Nova Zelândia (2010b).

72. Cf. Icomos-Espanha (2011).

73. Cf. Icomos-China (2015).

74. Icomos (1996, p.7).

75. Id., 2008a, p. 5.
É interessante perceber que a partir de 1983, mesmo com a noção de integridade não tão clara, alguns documentos passaram apresentar categorias de integridade, como é o caso da Carta de Appleton para a Proteção e Valorização do Ambiente Construído (1983): ${ }^{58}$ integridade estética, histórica, estrutural e tecnológica; da Carta Internacional sobre Turismo Cultural (1999):59 integridade física e ecológica; do Segundo Protocolo da Convenção de La Haya (1 999):60 integridade territorial; dos Princípios que devem reger a conservação das estruturas históricas em madeira (1999):01 integridade física e histórica; da Carta Australiana para o Patrimônio Natural (2002):62 integridade natural; da Declaração de San Miguel de Allende (2005):03 integridade sociofuncional, estrutural e visual; da Carta para Interpretação e Apresentação de Sítios de Patrimônio Cultural (2008):64 integridade física; e da Carta para a Conservação dos Sítios com Valor Patrimonial Cultural (2010): 65 integridade estrutural e funcional.

Essas variações de noção de integridade são um reflexo, principalmente a partir das décadas de 1990 e 2000, de estudos desenvolvidos principalmente por Jukka Jokilehto ${ }^{66}$ e Herb Stovel. ${ }^{67}$ Daí em diante, pesquisadores envolvidos não só com a temática da integridade, mas também com a da autenticidade, bem como os principais órgãos conservacionistas, passaram a tomar as ideias desses autores como fundamentos para a conservação do patrimônio.

Já o National Park Service, mediante seu entendimento de integridade, propôs as seguintes variações: "da localização, do design, do ambiente, dos materiais, da mão de obra, do sentir e de associação".68

A Declaração de San Antonio (1996), ${ }^{69}$ a Carta do Icomos para ltinerários Culturais (2008),70 a Carta da Nova Zelândia (2010),71 o Documento de Madrid $(2011)^{72}$ e os Princípios para a Conservação de Sítios Patrimoniais na China (2015), ${ }^{73}$ tomando por base as discussões e dentro de suas especificidades, tentaram se aproximar de uma noção de integridade, bem como sua aplicabilidade.

Declaração de San Antonio - Deve ser prestada maior consideração às provas de autenticidade para que possam ser identificados marcadores para a referida determinação, de forma tal que todos os valores significativos do sítio possam ser estabelecidos [...] Integridade. Ou seja, se o recurso está fragmentado; quanto é que falta, e quais são as suas condições recentes. ${ }^{74}$

Carta do Icomos para Itinerários Culturais - A constatação da integridade [...] deve ter por base, necessariamente, uma série de evidências e elementos tangíveis e intangíveis que constituam um testemunho suficientemente representativo do significado global do itinerário, que permitam uma representação completa das características e a importância dos processos históricos que os gerou, que transmitam a totalidade dos valores que representam o itinerário e que contribuam para explicar seu valor unitário como conjunto. ${ }^{75}$ 
Carta de Nova Zelândia para a Conservação de Lugares de Valor Cultural - Integridade significa a totalidade ou intactilidade de um lugar, incluindo o seu significado e sentido de lugar, e todos os atributos tangíveis e intangíveis e os elementos necessários para exprimir o seu valor patrimonial cultural. ${ }^{76}$

Documento de Madrid - Integridade é a medida da conservação do estado original na sua totalidade do patrimônio construído e seus atributos e valores. A análise do estado de integridade requer portanto uma avaliação de até que ponto o bem: i) inclui todos os componentes necessários para expressar o seu valor; ii) assegura a completa representação das características e processos que transmitem o significado do bem; e iii) sofre efeitos adversos de intervenções e/ou negligência. ${ }^{77}$

Princípios para a Conservação de Sítios Patrimoniais na China - $\bigcirc$ princípio da integridade enfatiza a importância de conservar os elementos mais significativos do patrimônio cultural, tanto em termos de tempo como de dimensões espaciais, incluindo o cenário de um local. ${ }^{78}$

Mesmo sabendo que todos esses documentos não se configuram como um conjunto homogêneo - e isso significa dizer que não se pode colocá-los no mesmo plano, até mesmo porque foram elaborados em períodos distintos, com finalidades diversas, tendo, portanto, intenções e repercussão bastante variadas -, percebe-se que para verificar a condição de integridade de um bem patrimonial alguns pontos são comuns, como representação completa das características, permanência de valores, estado original e significado.

Esses pontos reverberam a ideia de Jukka Jokilehto que considera que o conceito de integridade pode justificar a "reintegração das partes, o restauro estilístico ou a reconstrução", 79 porém esta deve ser entendida na perspectiva de leitura do todo, favorecendo uma melhor gestão do bem, e que possibilite o significado das diferentes partes integradas no contexto geral. Assim, a integridade configura-se como "a capacidade de uma propriedade de assegurar ou sustentar a sua importância ao longo do tempo" ${ }^{80}$

Antecipando todos esses documentos, tidos como oficiais, e no sentido de indicar medidas para a permanência da integridade em jardins históricos, consta nas recomendações do First International Symposium on Protection and Restoration of Historic Gardens de 1971 que, para garantir a integridade arquitetônica e vegetal, faz-se necessário:

Substituição de árvores e plantas, no momento oportuno (especial atenção ao restauro da arquitetura da árvore e da planta de acordo com o espírito originall);

Manutenção cuidadosa do décor arquitetônico e escultural, condições necessárias para a abertura dos jardins ao público. Eles não devem prejudicar seu valor histórico e artístico.
76. Icomos-Nova Zelândia (2010b, p. 10).

77. Icomos-Espanha (2011, p. 6).

78. Icomos-China (2015, p. 56).

79. Jokilehto (1995, p. 229).

80. Stovel (2007, p. 21). 
81. First International Symposium... (p. 231-232).

82. Carta de Florença (1981; art. 9).

83. Ibid., art. 12.

84. Região ambientalmente uniforme em condições para manter a flora e fauna juntos.

85. O principal sistema de interação, envolvendo tanto os organismos vivos quanto os seus ambientes físicos.

86. Cf. Jokilehto (2006b).
Não se deve tolerar nenhuma transformação arquitetônica ou vegetal contrária à composição do jardim e resistir a certas exigências do público. ${ }^{81}$

Contudo, a condição de integridade apresentada em 1971 foi convertida em autenticidade em 1981 no momento do Sixth International Symposium on Protection and Restoration of Historic Gardens, que resultou na elaboração da Carta de Florença (1981), onde consta que a autenticidade, no que se refere à vegetação, diz respeito à "escolha de vegetais" 82 e que "as espécies de árvores, arbustos, plantas e flores a serem substituídas periodicamente devem ser selecionadas em relação a práticas estabelecidas e reconhecidas em cada região botânica e hortícola e com o objetivo de determinar as espécies inicialmente cultivadas e preservá-las". ${ }^{83}$ Tal fato se deu porque a Carta de Florença foi constituída no sentido de complementar a Carta de Veneza (1964) que, por sua vez, direciona a conservação de um bem a uma cultura do respeito ao material original e aos documentos autênticos.

Em 1977, e considerando as ameaças de destruição que a cada dia enfrentava o patrimônio cultural e o natural, a Conferência Geral da Unesco aprovou a Convenção para a Proteção do Patrimônio Mundial Cultural e Natural, e, com isso, passou-se a considerar que o valor da integridade é tão importante quanto o valor da autenticidade de um sítio, mesmo a integridade sendo apresentada de forma embrionária em termos de conceituação e de metodologia para verificação.

A integridade e a autenticidade são eixos da conservação do patrimônio, tanto nos processos de identificação como nos de proteção legal em uma primeira fase, como em conservação, gestão e uso, em uma segunda fase. A integridade, empregada pela Unesco, foi importada da International Union for Conservation of Nature (IUCN) que tem por base o manejo do patrimônio natural, e que visa identificar os processos e elementos que constituem os componentes fundamentais dos ecossistemas necessários para a sua existência.

Em relação ao patrimônio natural, a condição de integridade está diretamente atrelada ao conceito de biótopo. ${ }^{84}$ Dentro de um habitat particular, os diferentes organismos que vivem juntos interagem formando um ecossistema ${ }^{85}$ dentro de sua própria integridade funcional. Em referência ao ambiente construído, e conforme Jokilehto, 86 a questão da integridade é relevante especialmente em relação aos processos de planejamento urbano e regional.

No âmbito do patrimônio cultural, somente em 2005 o Comitê do Patrimônio Mundial adota pela primeira vez, mediante a Decisão 20 COM IX.13, os 
parágrafos sobre integridade, e em sua versão das Diretrizes Operacionais consta: "A integridade é uma apreciação de conjunto e do carácter intacto do patrimônio natural e/ou cultural e dos seus atributos". ${ }^{87}$ Estudar as condições de integridade exige, portanto, que se examine em que medida o bem "possui todos os elementos necessários para exprimir o seu valor universal excepcional; é de dimensão suficiente para permitir uma representação completa das características e processos que transmitem a importância desse bem; sofre efeitos negativos decorrentes do desenvolvimento e/ou da falta de manutenção". 88

O impulso para introduzir integridade no âmbito da avaliação de sítios do patrimônio cultural deriva da reunião de peritos do patrimônio mundial em 1998 em Amsterdã e de seus esforços para o tratamento em conjunto do patrimônio natural e cultural. Assim, o emprego da integridade no patrimônio cultural é modelado, em certa medida, nos pressupostos do patrimônio natural.

Mesmo com a inclusão da integridade, pela Unesco, em suas diretrizes, poucas foram as reuniões que ocorreram para discutir o tema. De forma específica foram três. A primeira foi a Reunião do Grande Zimbábue (26-29 de maio de 2000); a segunda $\circ 1^{\circ}$ Congresso sobre Autenticidade e Integridade do Patrimônio Mundial das Américas (24-26 de agosto, 2005) e a terceira o Encontro internacional de expertos sobre integridade do patrimônio Cultural (12-14 de março de 2012 ). Também vale ressaltar o Simpósio Interamericano sobre a Autenticidade na Conservação e Gestão do Patrimônio Cultural (27-30 março de 1996), mesmo a integridade aparecendo como um "marcador" para a autenticidade.

A Reunião do Grande Zimbábue para a gestão dos bens do patrimônio cultural e natural centrou-se na autenticidade e na integridade num contexto africano, dando origem ao texto Authenticity and integrity in an African context: expert meeting, Great Zimbabwe, Zimbabwe. Mesmo tendo a intenção de aprofundar um entendimento da autenticidade e integridade, somente uma conferência tratou da integridade de modo isolado, e mesmo assim direcionada para o patrimônio natural. O binômio autenticidade/integridade prevaleceu nas demais conferências, porém com maior destaque para a autenticidade. Contudo, expressa a importância da ampliação do entendimento da integridade nas Diretrizes Operacionais da Unesco.

No México, o $1^{\circ}$ Congresso sobre Autenticidade e Integridade do Patrimônio Mundial das Américas reuniu especialistas que debateram questões sobre o patrimônio natural e cultural, tanto no aspecto material como no imaterial. De todo esse universo, duas conferências abordaram especificamente o tema da integridade, porém, aplicada ao patrimônio natural e misto da humanidade, e sem um aprofundamento do que já vem sendo, até o momento, discutido; e sete
87. Diretrizes Operacionais (2005, Art. 88, p. 40).

88. Ibid.. 
89. Cf. Jokilehto (2006 a; 2006b).

90. Cf. Jokilehto (2006a)

91. Cf. Jokilehto (2006b) envolveram a autenticidade e a integridade e, para esses casos, com exceção dos escritos de Jukka Jokilehto e Herb Stovel, a integridade ficou em segundo plano e, na maioria das vezes, só citada como algo importante para a conservação. Isso reflete, já nesse momento, a carência de estudos nessa área e a precipitação da Unesco em incluir a condição de integridade nas Diretrizes Operacionais.

O Simpósio Interamericano sobre a Autenticidade na Conservação e Gestão do Patrimônio Cultural que ocorreu em San Antonio, Texas, reuniu participantes dos comitês nacionais do lcomos da América do Norte, da América Central e da América do Sul para debater a aplicação dos conceitos do Documento de Nara de 1994 que trata da autenticidade. A reunião adotou a Declaração de San Antonio, que aporta recomendações com vista a alargar as provas de autenticidade, para incluir o reflexo do seu verdadeiro valor, a integridade, o contexto, a identidade, o uso e a função, além de recomendações sobre diferentes tipologias de sítios. Tratou das relações entre a autenticidade e a identidade, a história, os materiais, o valor social, os sítios dinâmicos e estáticos, a administração e a economia.

Em Al Ain, Emirados Árabes Unidos, o Encontro Internacional de Expertos sobre Integridade do Patrimônio Cultural desenvolveu uma reflexão profunda mediante três grupos temáticos de trabalho (cidades históricas e áreas urbanas; sítios arqueológicos, paisagens culturais e monumentos e grupos de edifícios) que levou em conta as decisões específicas do Comitê do Patrimônio Mundial em sua $33^{a}$ sessão (Sevilha, 2009, 33 COM/20) e em sua $35^{a}$ sessão (Paris, 201 1, 35 $\mathrm{COM} / 20$ ). Ante o que foi abordado e pelo aprofundamento, esse encontro se configura como o mais importante no debate da integridade.

A reunião advertiu a existência de uma variedade de "definições" sobre integridade, algumas sobre integridade funcional, integridade estrutural e integridade visual, como se definiu na Reunião de Expertos de La Vanoise, na França, em 1996, as quais foram tomadas de Jukka Jokilehto ${ }^{89}$ como: integridade sociofuncional, integridade estrutural e integridade visual. Outros possíveis aspectos de integridade se discutiram na reunião, onde se destacaram três "conceitos": (i) integridade da composição; (ii) integridade da estrutura, das relações e do visual; e (iii) integridade funcional.

Jukka Jokilehto em World Heritage: Defining the outstanding universal value ${ }^{90}$ e em Considerations on authenticity and integrity in world heritage context ${ }^{91}$ desenvolveu um escopo para a pesquisa sobre integridade olhando para a condição sociofuncional, visual, funcional, estrutural e histórica. 
A integridade sociofuncional de um sítio corresponde à identificação das funções e dos processos em que se baseou o seu desenvolvimento ao longo do tempo, tais como aqueles associados com a interação na sociedade, as respostas espirituais, a utilização dos recursos naturais e os movimentos dos povos. Já a integridade visual ajuda a definir os aspectos estéticos representados em um determinado lugar. ${ }^{92} \mathrm{~A}$ integridade funcional é evidente, particularmente, no caso de uma instalação industrial, tal como a fábrica, mas é igualmente relevante no tecido urbano e é importante para dar vida às áreas urbanas ou rurais, bem como quanto ao planejamento e gestão de sua utilização atual e proporciona a referência para a compreensão do significado dos diferentes elementos no ambiente construído. A integridade estrutural define a realidade atual no campo, isto é, os elementos que sobrevivem na condição histórica de hoje a partir das funções evolutivas do passado - uma paisagem de relíquia cultural, que também pode ser definida em termos da integridade histórica. ${ }^{93} \mathrm{E}$ em tais dimensões de integridade que se pode basear o desenvolvimento de um sistema de gestão de modo a garantir que os valores associados não sejam prejudicados.

Ressalta-se que a integridade visual apresentada por Jokilehto assemelha-se a integridade do design do National Park Service onde o "design é a combinação de elementos que criam a forma, o plano, o espaço, a estrutura e o estilo de um bem." 94 Assim, a integridade do design inclui elementos como organização do espaço, proporção, escala, tecnologia, ornamentação e materiais. Engloba considerações tais como sistema estrutural, arranjo dos espaços, padrão de fenestração, texturas e cores de materiais de superfície, tipo, quantidade e estilo ornamental e arranjo e tipo de plantações em uma paisagem projetada.

Essas variações de integridade, por assim dizer, abordadas por Jukka Jokilehto, foram base para a elaboração de uma proposta de Declaração de Significância apresentada no texto International charters on urban conservation: some thoughts on the principles expressed in current international doctrine de 2011. Apesar de uma série de discussões por parte de Jokilehto e Stovel, nos principais fóruns sobre patrimônio mundial, as questões sobre integridade ainda não foram incluídas nas diretrizes operacionais da Unesco.

Com a inclusão de um segundo conceito, o de qualificação, ou seja, a integridade aos requisitos formais do patrimônio mundial, especificamente para o patrimônio cultural, e a rejeição, em paralelo, do conceito de autenticidade na Convenção para a Salvaguarda do Patrimônio Imaterial (2003), que define o intangível para incluir espaços culturais tangíveis, o potencial para a confusão aumentou consideravelmente. Nas candidaturas apresentadas ao Icomos para revisão em 2006, esta é a área do documento de nomeação talvez mais
92. Cf. Jokilehto (2006a).

93. Cf. Jokilehto (2006b).

94. National Park Service (1990, p. 44). 
95. Cf. Carta de Florença (1981).

96. Cf. Unesco (1992). 97. Cf. Añón-Feliú (2005) problemática. Embora sejam explicados os requisitos de autenticidade e integridade desde as diretrizes operacionais de 2005, muitos Estados-partes não têm compreendido o que está sendo solicitado.

Ante tudo isso, as orientações técnicas da Unesco, na última revisão das Diretrizes Operacionais em 2016 (40 COM 1 1), não apresentam nenhuma modificação desde 2005; no que tange a integridade ainda está em curso a formulação de exemplos de sua aplicação aos bens que abarcam os critérios de (i) a (vi) apresentados no Art. 89. É importante perceber que dois dos quatro critérios estão relacionados à paisagem: criação de paisagem - critério (ii) [aqui podemos incluir os jardins] e a paisagem que ilustre um ou mais períodos significativos da história humana - critério (iv). O que mostra a complexidade da conservação do jardim histórico.

\section{INTEGRIDADE EM JARDINS HISTÓRICOS}

Ao incorporar ao jardim histórico as noções de monumento e monumento $v_{i v 0^{95}}$ e de paisagem cultural [criada intencionalmente pelo homem], ${ }^{96}$ as pesquisas sobre conservação de jardins históricos tomaram uma nova proporção, tanto em quantidade como em qualidade. Contudo, segundo Carmen Añón-Feliú, ${ }^{97}$ as primeiras práticas de intervenção em jardins históricos datam de quase dois séculos.

Entretanto, ainda é incipiente a produção científica que trata da conservação de jardins históricos, destacando-se os estudos de Ana Rita Sá Carneiro (Brasil), Carmen Añón-Feliú, José Tito Rojo e Mónica Luengo (Espanha), Cristina Castel-Branco (Portugal), Desideria Pasoline Dall'onda, Franco Panzini, Margherita Azzi Visentini, Maria Adriana Giusti y Mario Catalano (ltália), Géza Hajós (Austrália), Michel Baridon (França), Saúl Alcántara Onofre (México) e Sonia Beriman (Argentina).

Em caráter institucional ressaltam-se a importância da National Trust, do National Garden Scheme e do Royal Horticultural Society e do English Heritage, todas do Reino Unido; da Associação Portuguesa dos Jardins e Sítios Históricos, em Portugal; do Comité des Parcs et Jardins de France, do Conseil National des Parcs et Jardins e do Parcs et Jardins Fondation, todas da França; do Registro del Patrimonio de Interés Cultural, Espanha; do Instituto per il Catalogo e la Documentazione, Itália e do National Park Service, Estados Unidos. Todos esses 
órgãos e/ou instituições possuem legislações específicas no que tange a conservação e preservação de parques e jardins históricos.

É recorrente na literatura sobre conservação de jardins históricos, principalmente as direcionadas ao restauro, que o elemento que requer maior atenção é o vegetal, dada a sua dinâmica. A presença do elemento vivo como um dos fundamentos principais da composição do jardim faz com que ele seja uma obra de arte efêmera por estar ligado a uma ordem cronológica interior que define e regula o nascimento, o crescimento e a morte. Desta maneira, conforme Belloso, ${ }^{98}$ cada jardim leva impresso a data, imprecisa, de sua degradação e acaso. Ao chegar a sua plenitude e esplendor, inicia seu lento e, não tão pausado, declínio, o que o leva a ser considerado a expressão mais frágil do nosso patrimônio.

Em um dos primeiros artigos publicados na Itália sobre restauro de jardins históricos, Desideria Pasoline Dall'onda sintetiza bem o quanto é complexo trabalhar com o elemento vegetal de forma a manter o caráter projetual e afirma:

Assim, a partir da realidade de hoje, o jardim no curso dos séculos sofreu várias sobreposições e metamorfose vegetal, do que podemos deduzir que é necessário observá-lo e estudá-lo quase como um palimpsesto vegetal. 99

Como palimpsesto vegetal, o jardim histórico assume a conotação de um documento vivo que deve ser lido e interpretado de forma que as ações de conservação estejam atreladas à sua integridade e autenticidade. De acordo com Belloso, ${ }^{100}$ os jardins históricos que vemos hoje são fruto, em sua grande maioria, de restauros, recuperações e recriações/reconstruções, e ainda se acrescenta a reconstituição. $\bigcirc$ acerto dessas iniciativas e seu êxito dependem do entendimento de que os jardins históricos são processos e não resultados ou produtos, dada a natureza biológica. Tais ações têm por objetivo permitir a leitura da unidade.

$\bigcirc$ jardim histórico como obra de arte e como documento histórico possui - valor da marca do tempo, o que podemos correlacionar com a pátina das artes plásticas. Dessa forma, qualquer intervenção deve primar pela leitura de sua inteireza. Nesse sentido, a pátina é uma condição na qual "matéria e estética vão unidos: a matéria como origem do efeito e a estética enquanto ao resultado de se fazer visível". ${ }^{101}$

restauro e a reconstituição são ações abordadas na Carta de Florença (1981). ${ }^{102}$ No Art. 16 aparecem atreladas à ação de restauro as condições de respeitar a evolução e não privilegiar uma época à custa de outra, o que significa, em outras palavras, a conservação da integridade do jardim, mesmo essa terminologia não constando na carta. A reconstituição, por sua vez, só será possível
98. Cf. Belloso (2014).

99. Dall'onda (1975, p.30).

100. Cf. Belloso (2014).

101. Lobo (2009, p. 185).

102. Cf. Carta de Florença (1981). 
103. Cf. Panzini (2013).

104. Cf. Catalano; Panzini (1990).

105. Cf. Giusti (2004). se for fundada sobre vestígios ou sobre documentação irrefutável, porém se um jardim houver desaparecido totalmente e, quando apenas possuir elementos conjeturais de seus estados sucessivos, não se poderá empreender uma reconstituiç̦ão relevante da noção de jardim histórico (Art. 16 e 17).

De todas as ações acima citadas, a reconstituição é a que até hoje causa um grande desconforto entre os estudiosos de jardins. Um caso de grande repercussão foi a reconstituição dos jardins do Palácio Het Loo, Holanda (figura 2), entre os anos 1977 e 1984

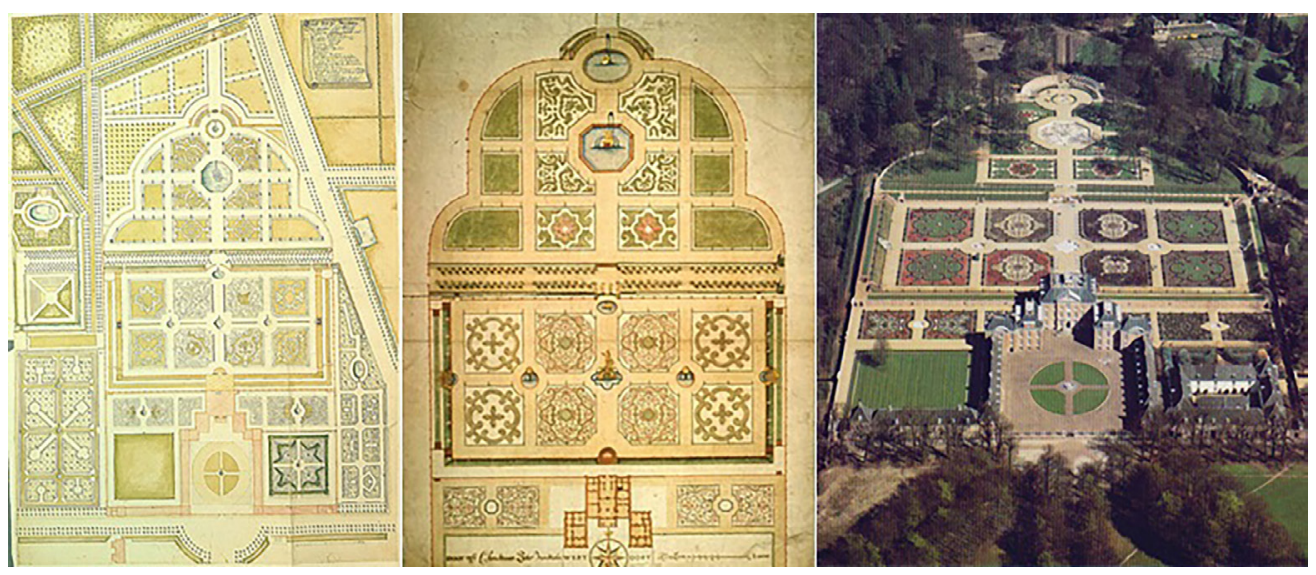

Figura 2 - Planos usados para a reconstituição do jardim do Het Loo. Da esquerda para a direita temos: desenho de T. Henry Reetz, 1706; desenho de C. P. Van Staden, ca. 1725; e o jardim após a reconstituição (1984). Fonte: De tuin van Rijks Museum Paleis Het Loo.

Conforme Franco Panzini, ${ }^{103}$ os jardins, em estilo Barroco e de formas híbridas, por apresentarem o gosto francês e holandês, que foram construídos sob a supervisão dos arquitetos Jacob Roman, da Holanda, e Daniel Marot, da França, entre os anos 1685 e 1692, passou a ser considerado um jardim histórico falso, justamente pelos questionamentos da ausência da autenticidade no nível material e da integridade no sentido da permanência das intenções projetuais. A reconstituição trouxe de volta o jardim holandês, então modificado durante a segunda metade do século XVII no momento da intervenção de Philip Willem Schonck, ao modo inglês, e sucessivamente durante a era napoleônica.

As intervenções pelas quais passaram os jardins do Het Loo possibilitaram trazer de volta o jardim tal como é apresentado em sua forma prístina, após uma análise exaustiva de todo o material iconográfico existente. ${ }^{104}$ Um histórico que é perfeito para a construção arquitetônica dos jardins, mas não para a essência de sua vegetação. Contudo, a arquiteta Maria Adriana Giusti, 105 especialista em restauro de parques e jardins históricos da Politecnico di Torino, considera que o 
princípio básico na intervenção dos jardins foi a autenticidade da imagem, que só foi possível pelo suporte da pesquisa documental.

Porém, essa autenticidade da imagem é passível de questionamento. Será que após uma reconstituição do jardim sua imagem está autêntica? Essa autenticidade diz respeito a que tempo histórico? $\bigcirc$ que ocorreu no Het Loo foi uma busca por uma aproximação da ideia de quem o projetou [intenção compositiva], até mesmo porque, e levando em conta a paleta vegetal do projeto original, algumas espécies não foram intr oduzidas no momento da reconstituição, assim, pode-se dizer que o jardim não está autêntico, mas íntegro, já que transmite a ideia do projetista. Esse caso recai no posicionamento de Brandi ${ }^{106}$ por considerar que "a matéria não será de modo algum a mesma, mas, sendo historicizada pela obra atual do homem, pertencerá a esta época e não àquela mais longínqua [...] e acabará, do mesmo modo, por constituir um falso histórico e estético".

Aliada à condição de o jardim histórico ser um monumento vivo está a dificuldade que os órgãos de preservação do patrimônio, principalmente no Brasil, têm em relação à conservação da vegetação, ou seja, alterar a paleta vegetal sem acarretar a perda dos atributos patrimoniais atrelados a ela e, consequentemente, aos valores.

Um exemplo claro dessa situação está evidenciado na Ata da $23^{a}$ Reunião do Conselho Consultivo do Patrimônio Cultural do Instituto do Patrimônio Histórico e Artístico Nacional (Iphan) ocorrida em 10 de agosto de 2000, momento em que foi proposto o tombamento do Conjunto Histórico no Bairro da Luz, em São Paulo (Brasil), Processo no. 1.463 -T- 00, e a rerratificação da delimitação da poligonal de tombamento do Sítio Roberto Burle Marx e tombamento das suas coleções museológicas e bibliográficas, no Rio de Janeiro (Brasil), Processo no. 1.13 1-T-84. Vale salientar que o sítio já possuía o tombamento provisório concedido na $113^{\circ}$ reunião em 22 de janeiro de 1985.

A proposta de rerratificação da delimitação da poligonal de tombamento do Sítio Roberto Burle Marx e tombamento das suas coleções museológicas e bibliográficas foi apresentada pelo conselheiro arquiteto Ítalo Campofiorito. $\mathrm{Na}$ ocasião, o conselheiro enfatizou a importância da conservação das espécies vegetais, bem como dos princípios artísticos de Roberto Burle Marx presentes na concepção do sítio, já que o via como um jardim, o que causou vários questionamentos entre os demais conselheiros.

conselheiro arquiteto e urbanista Nestor Goulart Reis Filho ressaltou sua preocupação com os processos de tombamento de jardins e, tomando como exemplo o caso do Jardim da Luz, questionou no momento "[... qual jardim da Luz tombaremos?" 
107. Iphan (2000, p. 15).

108. Ibid

109. Ibid., p. 16.

110. Ibid.

111. Iphan (2000, p. 17).

112. Ibid., p. 18. e "[... quando vamos começar a tombar jardins no Brasil com conhecimento de causa e controle técnico?"107 Essas questões partiram da preocupação de o jardim ser uma arte efêmera, já que quando se tombam "a casa, os quadros, os objetos e o ambiente, que daqui a cem anos certamente estarão lá [...] $\bigcirc$ jardim é uma coisa muito fácil de comer pelas bordas. Então, qual é a garantia de que o jardim do Burle Marx terá a mesma forma, passados cinquenta anos?"108

Para essas questões Ítalo Campofiorito explicou que o jardim não tem a condição de permanecer imutável - "são coisas vivas. Mas da forma como um jardinista pode esperar que um jardim se preserve, ele será preservado". ${ }^{109}$ Assim, a conservação do jardim do Sítio Roberto Burle Marx se fará "[...] mantendo o desenho original [...] Se no futuro irão respeitá-lo ou não, é o mesmo problema para qualquer outra obra de arte". ${ }^{110}$

De tal modo, o conselheiro e advogado Joaquim Falcão, ao considerar pertinentes os questionamentos, sugeriu que:

[...] quando tombamos um jardim, deveríamos ter igual documentação e deveríamos pautar uma política de preservação mantendo o projeto original. As plantas perecem e devem ser renovadas, as mesmas espécies com os mesmos desenhos [...] seria importante fazer um levantamento não apenas das espécies, mas da disposição das espécies, do projeto e da concepção paisagística das espécies. ${ }^{111}$

Ao final da $23^{\circ}$ Reunião do Conselho Consultivo do Patrimônio Cultural do Iphan, e depois de tantos questionamentos sobre a conservação de jardins, o conselheiro Nestor Goulart chega à seguinte conclusão: "Não temos padrões de conservação de jardins públicos. Deveríamos dispor de um manual, com um mínimo de critérios [...] não sabemos como conservá-los", ${ }^{112}$ situação que até hoje permanece.

Embutido nas falas dos conselheiros está o sentido de integridade e autenticidade, tanto do conjunto como da vegetação em si. No âmbito da conservação de jardins históricos, essas condições aparecem com muita frequência na literatura especializada, mas não entendida na mesma medida, não chegando a uma definição e tampouco a uma metodologia que possibilite a verificação da integridade e da autenticidade.

Um ponto muito discutido entre os estudiosos de jardim histórico é a questão da substituição de indivíduos vegetais, seja pelo depauperamento ou pelo plantio desordenado sem respeitar o projeto original. Essa questão fez com que surgissem, entre os conservadores de jardins, dois grupos de pensamento. 
primeiro grupo considera fundamental a substituição dos indivíduos vegetais, desde que estes estejam em conformidade com as especificações do projeto original, de forma a manter inalterada a intenção artística do projetista, ou seja, a autenticidade como prioridade. Diante disso, surgem algumas questões: o que fazer quando uma espécie já não mais se adapta ao jardim? E quando não mais se permite, por barreiras fitossanitárias, a exportação e/ou importação de determinada espécie de um país para o outro e/ou entre estados do mesmo país? Será que tais espécies não podem ser substituídas por outras com características plásticas semelhantes?

segundo grupo prioriza o valor de antiguidade dos indivíduos vegetais, de forma que mesmo que eles não pertençam às espécies indicadas no projeto original, mas, se imprimirem, por sua característica morfológica externa, uma plástica semelhante ao que foi idealizado pelo projetista, ou seja, a imagem, devem permanecer no jardim. Aqui, o direcionamento está em garantir a integridade do conjunto e não a autenticidade do material. $\bigcirc$ que corrobora com o posicionamento de Brandi ${ }^{13}$ ao entender que o papel da matéria na imagem "deriva de não se ter reconhecido a importância da matéria como estrutura, chegando ao mesmo resultado de assimilar o aspecto à forma, mas dissolvendose como matéria [...] a matéria permite a manifestação da imagem".

Exemplos dessa situação podemos ver na Praça de Casa Forte (Brasil), onde para o jardim de plantas exóticas Burle Marx especificou o plantio da Lagerstroemia indica (rosedá), porém, o que hoje encontramos são indivíduos de Lagerstroemia speciosa (rosedá-gigante) e, na Praça Ministro Salgado Filho (Brasil), também projeto de Burle Marx, que no momento do restauro foi decidida a substituição da Caesalpinia echinata (pau-brasil) pela Caesalpinia peltophoroides (sibipiruna), devido a não adaptação da Caesalpinia echinata na área diante da mudança microclimática e dos fatores antrópicos relacionados ao alto nível de polvição ${ }^{114}$ (figuras 3 e 4).

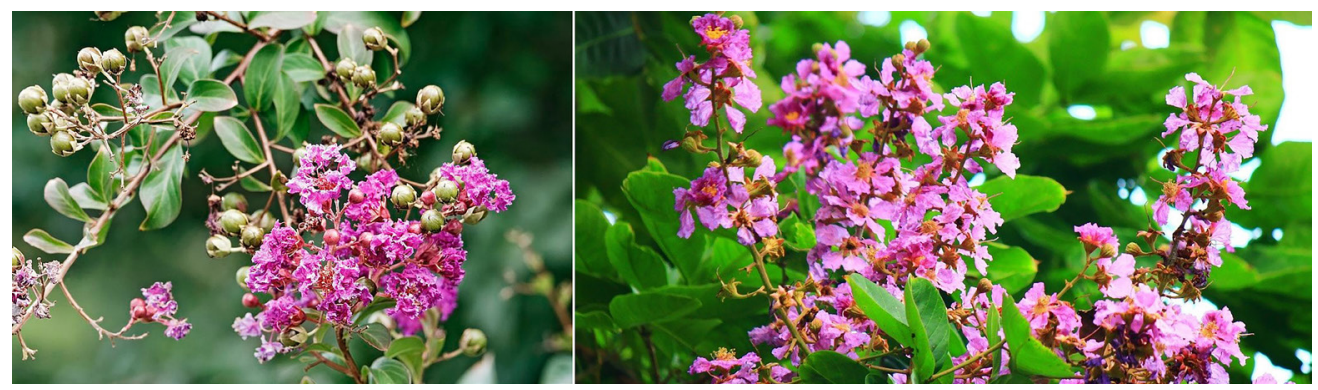

Figura 3 - Comparação entre Lagerstroemia indica (à esquerda) e Lagerstroemia speciosa (à direita), Praça de Casa Forte. Fotografia: Joelmir Marques da Silva.
113. Brandi (2004, p. 39).

114. Cf. Sá Carneiro et al. (2015). 

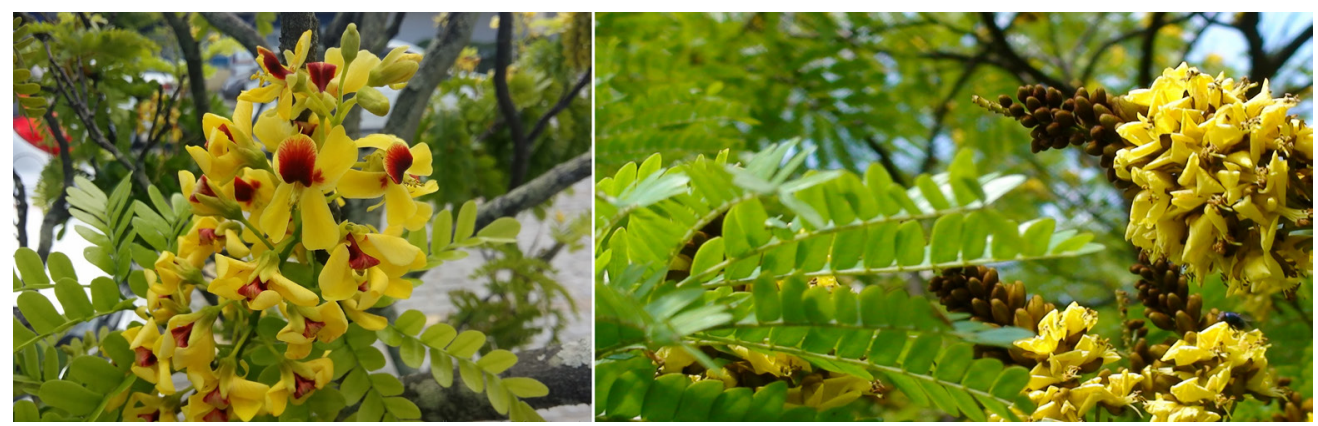

Figura 4 - Comparação entre Caesalpinia echinata (à esquerda) e Caesalpinia peltophoroides (à direita), Praça Ministro Salgado Filho. Fotografia: Joelmir Marques da Silva.

Desta forma, a autenticidade não está presente na matéria [espécies vegetais], mas a integridade visual sim, aqui fazendo-se uso de uma das categorias de integridade adotada em muitos documentos patrimoniais e discutida por Jukka Jokilehto e pelo National Park Service, pela similaridade da arquitetura vegetal e pela plasticidade das folhas, flores e frutos, porém com algumas diferenças em sua morfologia externa. Vantagem essa proporcionada pela aproximação taxonômica por pertencerem ao mesmo gênero botânico.

Mesmo sendo tão recorrente na literatura a importância da integridade e da autenticidade para a conservação do jardim histórico, ainda existe em nível mundial uma brecha no que tange a uma metodologia de verificação. No plano patrimonial, e em uma realidade brasileira, basta olharmos para as Atas do Conselho Consultivo do Patrimônio Cultural do Iphan.

Em 2015 ocorreram os tombamentos do Campo de Santana, projetado por Auguste François Marie Glaziou em 1873, no Rio de Janeiro; e de seis jardins de Burle Marx no Recife: Praça de Casa Forte (1935), Praça Euclides da Cunha (1935), Praça do Derby (1936), Conjunto Jardim do Palácio do Campo das Princesas e Praça da República (1936), Praça Ministro Salgado Filho (1957) e Praça Faria Neves (1958). O interessante é que na Ata do Conselho Consultivo (79 Reunião), os responsáveis pela elaboração dos processos não trazem a questão da conservação para uma discussão com os conselheiros do Iphan e nem eles, por sua vez, abrem o questionamento, diferentemente do que ocorreu em 2000 para o caso do Sítio Roberto Burle Marx e do Jardim da Luz.

Ao analisar de modo específico o Parecer $n^{\circ}$. 1.563-T-08, para os jardins de Burle Marx, no Recife, percebe-se que a narrativa foi construída tomando por base a historicidade - de quem idealizou e do conjunto da obra -, e não se faz menção à condição de conservação desses sítios. $\bigcirc$ que nos leva à questão de 
que, para um bem ser tombado, uma das premissas, conforme Carlos Fernando de Moura Delphim, ${ }^{115}$ é verificar o quão integro e autêntico ele é.

$\bigcirc$ não entendimento da noção de integridade e de autenticidade vem acarretando nos especialistas em restauro de jardins históricos uma supervalorização da condição de autenticidade, e isso percebemos claramente quando analisamos, principalmente, projetos de restauro em que sempre se destacam os esforços para conseguir a mesma espécie vegetal, o mesmo material, e isso também está atrelado ao fato de a Carta de Florença (1981) ser fielmente seguida pelos conservadores, no sentido de que, ao respeitar as diretrizes da carta, que trata da autenticidade, as ações de conservação são validadas. Ainda que a integridade e a autenticidade sejam, de certa forma, complementares no sentido da matéria e do que se vê, a ausência de uma não significa, necessariamente, a ausência da outra.

Tomamos como exemplo um quadro que passou por um processo de restauro (figura 5). A parte que foi restaurada é um acréscimo. Em sua totalidade este quadro não está mais autêntico, mas, ao olharmos para ele vemos a inteireza do conjunto, porque a obra nos passa a mensagem intencionada pelo artista, ou seja, foi reparada a "ação degenerativa ou, em qualquer caso, modificadora do tempo". 116 É, nessa perspectiva que temos que ver o jardim.
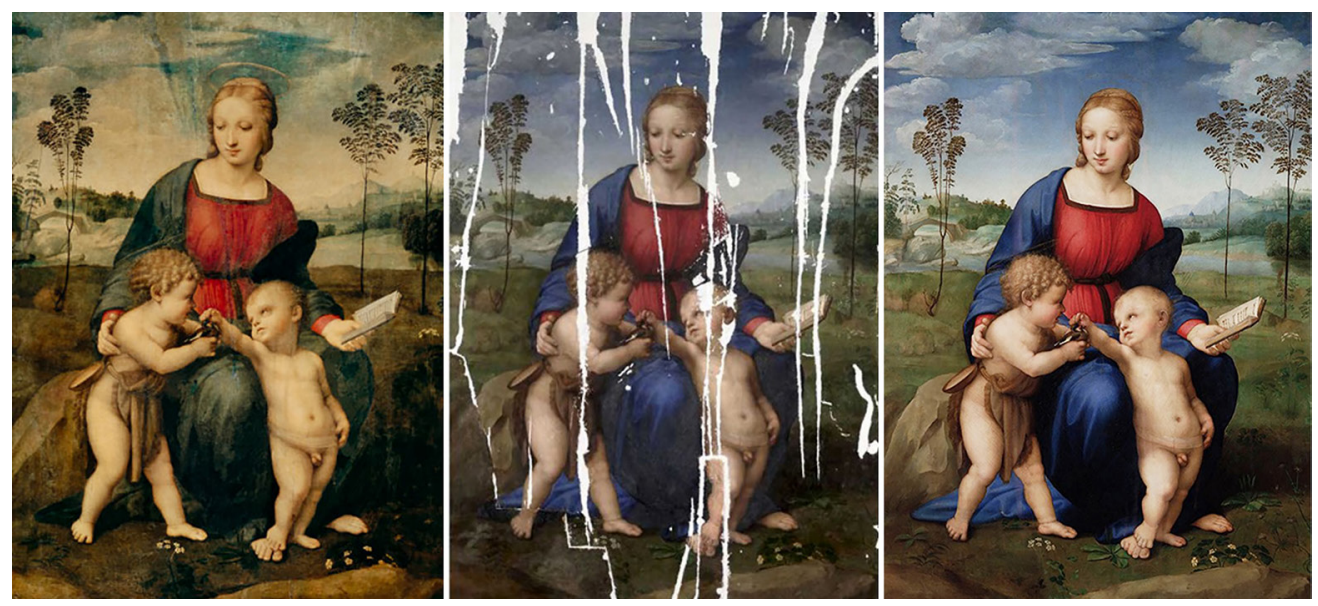

Figura 5 - Rafael Sanzio. Madonna del Cardellino, ca., 1506 lóleo sobre tela de $107 \mathrm{~cm} \times 77$ $\mathrm{cm})$. Restauro de Patrizia Riitano do departamento de pinturas do Opificio Delle Pietre Dure de Florença. Acervo: Opificio delle Pietre Dure.

No Brasil, a integridade direcionada aos jardins históricos vem sendo, de certa maneira, abordada desde 1999 quando se publicou a primeira versão do Manual de intervenção em jardins históricos e que foi revisto e republicado em 2005 sob a organização de Carlos Fernando de Moura Delphim, técnico do Iphan. Mesmo existindo 
117. Delphim (2005, p. 29); Carta de Juiz... (2010, p. 4).

118. Carta de Juiz... (2010, p. 3).

119. Ibid. (p. 2). um espaço temporal de seis anos entre a primeira e segunda versão do manual, a definição de integridade permaneceu a mesma. Evidencia-se, também, que no momento da elaboração da Carta dos Jardins Históricos Brasileiros dita Carta de Juiz de Fora, em 2010, a definição de integridade apresentada é a mesma do manual de 2005:

[... ] a integridade depende do grau de equilíbrio que os elementos que o compõem mantêm entre si. O conjunto de elementos que configuram um sítio histórico forma uma unidade básica. A partir dessa compreensão, pode-se descrever cada elemento, cada parte, tendo por base a intenção original. A integridade se refere ao quanto o bem é composto e ao quanto preserva do equilibrio entre os diversos elementos componentes. Suas qualidades intrínsecas estão relacionadas à qualidade dos materiais, a sua construção, desenho e localização. ${ }^{117}$

Contudo, o que vemos tanto no Manual de intervenção em jardins históricos como na Carta dos Jardins Históricos Brasileiros é uma definição resumida da noção de integridade apresentada pela Unesco, que como vimos está em sua fase embrionária, principalmente para os jardins históricos. Nesta carta também é questionável a noção de autenticidade do jardim histórico por considerar que "depende de quanto seus materiais são originais ou genuínos", 118 o que contradiz com a condição de jardim histórico nela assumida: "nos jardins, natureza e história são elementos vivos e dinâmicos em incessante mutação [...]". 119

O que importa aqui é entender que a integridade vai muito além do entendimento do grau de equilíbrio entre os elementos que compõem o jardim, assim como nem sempre estará relacionada à qualidade dos materiais, principalmente se o material for vegetal.

Dessa forma, devemos sair da cultura da replicação de definições, avançar nos estudos de jardins históricos e sair das contradições. Tomar por base o que já foi dito e reconstruíto sob nova óptica é o necessário.

\section{CONSIDERAÇÕES}

A integridade é uma condição, junto com a autenticidade, para testificar significância cultural de um bem patrimonial e, assim, expressar a excepcionalidade para ser declarado patrimônio mundial da humanidade. Contudo, ao longo dos anos, o entendimento e a criação de procedimentos para verificar a integridade e a autenticidade vem sendo discutidos no âmbito do patrimônio cultural e natural, 
porém, no que se refere aos jardins históricos, esse entendimento se encontra em fase embrionária, principalmente ante todas as variações de integridade existentes.

Não é possível imaginar que podemos congelar as plantas, que elas não morrerão. Elas têm uma dinâmica própria. Portanto, é um grande desafio a definição de conceitos e métodos de verificação de atributos, a exemplo da integridade, que se conciliem com as transformações do jardim.

Ao considerarmos a vegetação a principal matéria do jardim histórico, e sendo ela capaz de transmitir sua imagem, a integridade visual é considerada, até então, a mais indicada para a verificação e, consequentemente, a conservação da ideia [princípios de composição] de quem o projetou.

Assim, a integridade visual de um jardim histórico é aquela que permite ao especialista perceber e sentir uma emoção estética favorecida pela presença da ideia de quem o concebeu, e sua presença garantirá a autenticidade do bem. Dessa forma, a integridade visual do jardim histórico independe da autenticidade das espécies vegetais [matéria] desde que as novas espécies possuam uma aproximação plástica com às do projeto original.

Para levar a cabo a verificação e a conservação da integridade visual de um jardim histórico, se faz necessário conhecer sua história de forma mais detalhada possível. Enquanto para outras criações artísticas - como, por exemplo, a arquitetura, a pintura e a escultura -, a obra em si constitui a referência primária de toda a investigação cognitiva, tal condição é válida só em parte para o jardim histórico, porque nele o tempo é o elemento criador e o modifica constantemente e, dessa forma, os conceitos estabelecidos para conservação de obras de arte não podem ser aplicados literalmente nos jardins históricos.

Assim, os jardins históricos pedem uma metodologia de análise própria, principalmente para a integridade, que supere a própria disciplina histórica, uma vez que não se data uma planta da mesma maneira, por exemplo, que se data um quadro e, com isso, tornar possível uma coexistência pacífica de diversos tempos, principalmente o tempo biológico da maturidade da vegetação e as transformações pelas quais passa o jardim e, assim, vemos a importância do entendimento do palimpsesto.

O palimpsesto vegetal, formado a partir da fitocronologia do jardim histórico, 120 torna-se um instrumento de primordial importância, iá que fornecerá a paleta vegetal histórica, bem como as camadas do tempo, o que permite o tratamento das lacunas de forma acertada, garantindo, assim, meios para verificação e conservação da integridade visual que garantirá que não se cometa um falso histórico ou artístico e, assim, a permanência de seus atributos e, consequentemente, os valores patrimoniais e sua significância.
120. Para mais informações sobre palimpsesto vegetal e fitocronologia cf. Silva et al. (2019). 


\section{REFERÊNCIAS}

FONTES ICONOGRÁFICAS

SANZIO, Rafael. Madonna del Cardellino, ca., 1506 (óleo sobre tela de $107 \mathrm{~cm} \mathrm{x} 77 \mathrm{~cm}$ ). Restauro de Patrizia Riitano do departamento de pinturas do Opificio Delle Pietre Dure de Florença. Acervo: Opificio delle Pietre Dure.

LIVROS, ARTIGOS E TESES

AÑÓN-FELIÚ, Carmen. El jardín histórico: notas para una metodologia previa al proyecto de recuperación. In: Jardins et Sites Historiques. Madrid: Doce Calles; Icomod/Unesco, 1993, p. 312-325.

AÑóN-FELIÚ, Carmen. La restauración de los jardines históricos. Anais... La doctrina de la restauración a través de las cartas internacionales, 2005.

BALDINI, Umberto. Teoría de la restauración y unidad de metodología. Hondarribia: Nerea, 2002.

BElloso, José Carlos Sanz. Jardines históricos. (Ponencia). Curso abierto de especialización en paisaje, Valladolid, 2014.

BERJMAN, Sonia. El paisaje y el patrimonio. Revista ICOMOS/UNESCO, [s. v.], p. 1-11, 2001.

BRANDI, Cesare. Teoria da restauração. Cotia: Ateliê, 2004.

CARBONARA, Giovanni. Avvicinamento al restauro: teoria, storia, monumenti. Napoli: Liguori, 1997.

CARRERA, Gamboa Eduardo; UVIÑA, Francisco; FIGARI, Jenny. integridad y autenticidad em la conservación de la Arquitectura de tierra, en los sitios arqueológicos de Cajamarquilla, Perú; paquimé, México, y coronado State monument, EE.UU. Tecni Tierra, Colombia, n. 36, p. 1-14, 2009. 
CARTA DE FLORENÇA (1981). In: CURY, I. (Brasil). Cartas Patrimoniais. 2. ed. Rio de Janeiro: Iphan, 2000. p. 253-258. Edições do Patrimônio.

CARTA DE JUIZ DE FORA (2010). Instituto do Patrimônio Histórico e Artístico Nacional (Iphan). Recife: Iphan, 2010.

CARTA DE VENEZA (1964). In: CURY, I. (Brasil). Cartas Patrimoniais. 2. ed. Rio de Janeiro: Iphan, 2000. p. 91-96. Edições do Patrimônio.

CARTA ITALIANA DO RESTAURO (1931/1932). Conselho superior para a antiguidade e as belas artes, 1931-1932.

CATALANO, Mario; PANZINI, Franco. Giardini storici: teoria e tecniche di conservazione e restauro. Roma: Officina, 1990.

CONAN, Michel. Antoine-Joseph Dézallier d'Argenville (1680-1765). In: Racine Michel. Créateurs de jardins et de paysages en France de la Renaissance au XXI siècle. Paris: Actes Sud, 2001, p. 96-106.

DALL'ONDA, Desideria Pasoline. Restauto del verde storico nella pianificazione del território, Italia Nostra, n. 128, p. 33-42, 1975.

DECLARAÇÃO DE SAN MIGUEL DE ALLENDE. Instituto Nacional de Antropologia e História. Cidade do México: INAH, 2005.

DELPHIM, Carlos Fernando de Moura. Intervenções em jardins históricos: manual. Brasília: Iphan, 2005.

FEILDEN, Bernard Melchior. Conservation of Historic Buildings. Oxford: Elsevier Butterworth-Heinemann, 2004.

GIOVANNONI, Guistavo. Verbete: Restauro dei Monumenti. In: Enciclopedia Italiana di Scienze, Lettere ed Arti. Roma: Istituto della Enciclopedia Italiana (Treccani), 1936, v. 18, p. 191-204.

GIUSTI, Maria Adriana. Restauro dei Giardini: teorie e storia. Firenze: Alinea, 2004.

INSTITUTO DO PATRIMÔNIO HISTÓRICO E ARTÍSTICO NACIONAL (IPHAN). Ata da $23^{a}$ reunião do conselho consultivo do patrimônio cultural. Brasília: Iphan, 2000. 
INTERNATIONAL COUNCIL OF MUSEUMS (ICOM). The Conservator-Restorer: a Definition of the Profession, 1984. Disponível em: <https://bit.ly/3604ZHB>. Acesso em: 20 maio 2016.

INTERNATIONAL COUNCIL ON MONUMENTS AND SITES (ICOMOS). Declaração de San Antonio. San Antonio: Icomos, 1996.

INTERNATIONAL COUNCIL ON MONUMENTS AND SITES (ICOMOS). Carta Internacional sobre Turismo Cultural. México: Icomos, 1999a.

INTERNATIONAL COUNCIL ON MONUMENTS AND SITES (ICOMOS). Princípios que devem reger a Conservação das Estruturas Históricas em Madeira. México: Icomos, 1999b.

INTERNATIONAL COUNCIL ON MONUMENTS AND SITES (ICOMOS). Carta de itinerarios culturales. Quebec: Icomos, 2008a.

INTERNATIONAL COUNCIL ON MONUMENTS AND SITES (ICOMOS). Carta Icomos para Interpretación y Presentación de Sitios de Patrimonio Cultural. Quebec: Icomos, 2008b.

INTERNATIONAL COUNCIL ON MONUMENTS AND SITES (ICOMOS-Canadá). Carta de Appleton. Ottawa, Canadá: Icomos, 1983.

INTERNATIONAL COUNCIL ON MONUMENTS AND SITES (ICOMOS-CHINA). Principles for the Conservation of Heritage Sites in China. Madri: Icomos, 2015.

INTERNATIONAL COUNCIL ON MONUMENTS AND SITES (ICOMOS-ESPANHA). Madrid Document. Madri: Icomos, 2011.

INTERNATIONAL COUNCIL ON MONUMENTS AND SITES (ICOMOS NEW ZEALAND). Carta para a conservação dos sítios com valor patrimonial cultural. Auckland, Nova Zelândia: Icomos, 2010a.

INTERNATIONAL COUNCIL ON MONUMENTS AND SITES (ICOMOS NEW ZEALAND). New Zealand Chapter. Auckland, Nova Zelândia: Icomos, 2010b.

INTERNATIONAL COUNCIL ON MONUMENTS AND SITES (ICOMOS); INTERNATIONAL UNION FOR CONSERVATION OF NATURE (IUCN). Declaracion de San Miguel de Allende. Guanajuato: INAH, 2005.

INTERNATION COUNCIL OF MONUMENTS AND SITES (ICOMOS); INTERNATIONAL FEDERATION OF LANDSCAPE ARCHITECTS (IFLA). Recommandations. In: First 
International Symposium on Protection and Restoration of Historic Garden, 1971, Fontainebleau. Anais... Fontainebleau: Icomos; Ifla, 1971. p. 37-42.

INTERNATIONAL UNION FOR CONSERVATION OF NATURE (IUCN). Carta Australiana para o Patrimônio Natural. Gland, Suíça: IUCN, 2002.

JOKILEHTO, Jukka; FEILDEN, Bernard. Management Guidelines for World Cultural Heritage Sites. [s. 1.]: Unesco; Icomos - Iccrom, 1993.

JOKILEHTO, Jukka. Comments on the Venice Charter with illustrations. Scientific Journal, n. 4, p. 61-76, 1994.

JOKILEHTO, Jukka. Reconstruction of ancient ruins. Conservation and Management of Archaeological Sites, v. 1, p. 69-71, 1995.

JOKILEHTO, Jukka. History of Architectural Conservation. Oxford: ButterworthHeinemann, 2002.

JOKILEHTO, Jukka. Conservation of World Heritage towns: the case of mining towns. In: International symposium on the Iwami Ginzan silver mine sites, Shimane Prefecture, p. 13-18, 2004.

JOKILEHTO, Jukka. Considerations on authenticity and integrity in World heritage context. In: LÓPEZ MORALES, Francisco Javier. Nuevas miradas sobre la autenticidad e integridad en el patrimonio mundial de las Américas, San Miguel de Allende, [s. v.], p. 35-48, 2005.

JOKILEHTO, Jukka. Considerations on authenticity and integrity in world heritage context. City E Times, v. 2, n. 1, p. 1-16, 2006 a.

JOKILEHTO, Jukka. World Heritage: defining the outstanding universal value. City \& Times, v. 2, n. 2, p. 1-10, 2006b.

JOKILEHTO, Jukka. International charters on urban conservation: some thoughts on the principles expressed in current international doctrine. City \& Time, v. 3, n. 2, p. 23-42, 2007.

KÜHL, Beatriz Mugayar. Preservação do patrimônio arquitetônico da industrialização: problemas teóricos de restauro. São Paulo: Ateliê, 2008.

KÜHL, Beatriz Mugayar. Notas sobre a Carta de Veneza. Anais do Museu Paulista. São Paulo. v. 18 , n. 2, p. 287320 , jul.-dez. 2010. 
LEE, Ronald Freeman. The preservation of historic and architectural monumentsin the United States. In: UNESCO. Meeting of expert on sites and monuments of art and history. Paris: Unesco, 1949, p. 1-11.

LOBO, María Jesús Martín. La pátina en la pintura de caballete: siglos XVII-XX. Donostia-San Sebastián: Nerea, 2009.

LUCIANI, Roberto. Il restauro: storia, teoria, tecniche, protagonisti. Roma: Fratelli Palombi, 1988.

MONTEIRO, Antonio; CASTEL-BRANCO, Cristina; FONSECA, Luís. Restauro e manutenção: apogeu e declínio de um jardim (1999). In: CASTEL-BRANCO, Cristina (coord.). Jardim Botânico da Ajuda. Lisboa: A.A.J.B.A.; Livros Horizonte, 1999.

NATIONAL PARK SERVICE. Technical information on the the National Register of Historic Places: survey, evaluation, registration, and preservation of cultural resources. Washington (DC): National Park Service, 1990.

OLIVEIRA, Ana Rosa. Tantas vezes paisagem. Rio de Janeiro: Faperj, 2007.

PANZINI, Franco. Projetar a natureza. São Paulo: Senac, 2013.

RUSKIN, John. A Lâmpada da Memória. Tradução e apresentação Maria Lucia Bressan Pinheiro; revisão Beatriz Mugayar Kühl e Gladys Mugayar Kühl. Cotia: Ateliê Editorial, 2008.

SÁ CARNEIRO, Ana Rita; SILVA, Joelmir Marques da; DUARTE, Mirela; AMORIM, Giseli. A conservação de um jardim de Burle Marx: Praça Ministro Salgado Filho. Bitácora Urbano Territorial, v. 25, n. 2, p. 43-50, 2015.

SILVA, Joelmir Marques da. Integridade visual nos monumentos vivos: os jardins históricos de Roberto Burle Marx. 2017. Tese (Doutorado em Desenvolvimento Urbano) Departamento de Arquitetura e Urbanismo, Universidade Federal de Pernambuco, Recife, $2017 a$.

SILVA, Joelmir Marques da. De Jardim Ordinário a Monumento Vivo. Revista Espaço Acadêmico, v. 17, n. 211, p. 17-31, 2017b.

SILVA, Joelmir Marques da; SÁ CARNEIRO, Ana Rita; FEITOSA-JÚNIOR, Wilson de Barros; ROLIM, Maria Eduarda Dantas de Oliveira. A Praça de Casa Forte: um jardim histórico, um 
patrimônio cultural do Brasil. Anais do Museu Paulista: História e Cultura Material [internet], v. 27,1-30. Disponível em: <https://bit.ly/2r0pXqN>. Acesso em: 5 abr. 2019.

STOVEL, Herb. Considerations in Framing the Authenticity Question for Conservation. In: Proceedings of the Nara Conference on Authenticity in relation to the World Heritage Convention. UNESCO WH Centre - Agency for Cultural Affairs (Japan) - ICCROM - ICOMOS, p. 393$398,1995$.

STOVEL, Herb. An overview of emerging authenticity and integrity requirements for Word Heritage nominations. In: LÓPEZ MORALES, Francisco Javier. Nuevas miradas sobre la autenticidad e integridad en el patrimonio mundial de las Américas, San Miguel de Allende, [s. v.], p. 35-48, 2005.

STOVEL, Herb. Effective use of authenticity and integrity as world heritage qualiifying conditions. City E Time, v. 2, n. 3, p. 21-36, 2007.

UNITED NATIONS EDUCATIONAL, SCIENTIFIC AND CULTURAL ORGANIZATION (UNESCO). The Operational Guidelines for the Implementation of the World Heritage Convention. Paris: Unesco, 1992.

UNITED NATIONS EDUCATIONAL, SCIENTIFIC AND CULTURAL ORGANIZATION (UNESCO). Segundo Protocolo à Convenção de Haia de 1954 para a Proteção da Propriedade Cultural em Caso de Conflito Armado. Paris: Unesco, 1999.

UNITED NATIONS EDUCATIONAL, SCIENTIFIC AND CULTURAL ORGANIZATION (UNESCO). The Operational Guidelines for the Implementation of the World Heritage Convention. Paris: Unesco, 2005.

VIOLLET-LE-DUC, Eugène. Restauração. $3^{\mathrm{a}}$ ed. Trad. Beatriz Mugayar Kühl. São Paulo: Artes \& Ofícios; Ateliê, 2007.

VON DROSTE, Bernd; BERTILSSON, Ulf. Authenticity and World Heritage. In: Proceedings of the Nara Conference on Authenticity in relation to the World Heritage Convention. UNESCO WH Centre - Agency for Cultural Affairs (Japan) - ICCROM - ICOMOS, 1995.

Artigo apresentado em 1\%1/2019. Aprovado em 13/9/2019.

\section{(cc) BY}

All the contents of this journal, except where otherwise noted, is licensed under a Creative Commons Attribution License 